\title{
Sea Level Variation at Western Coast of Mexican Pacific in Response to Tsunamigenic Earthquakes (2012-2015)
}

\author{
Román Rodolfo Vera-Mendoza ${ }^{1}$ and Modesto Ortíz-Figueroa ${ }^{2}$ \\ 1. Centro de Alerta de Tsunamis, Secretaría de Marina, Av. Heroica Escuela Naval Militar No. 861. Col. Los Cipreses, Del. \\ Coyoacán, D.F., 04830, México \\ 2. Centro de Investigación Científica y Educación Superior de Ensenada (CICESE), Km 107 Carretera Tijuana-Ensenada, Ensenada, \\ Baja California, 22860, México
}

\begin{abstract}
Tsunamis in Mexico are a real threat, still unknown to many, mainly by people living in or visiting the coast. The Tsunami Warning Center in Mexico recently created (September 19, 2011) monitors earthquakes and sea level change caused by these same. Sea level on the west coast of the Mexican Pacific was analyzed after the occurrence of local, regional and distant earthquakes, in order to determine the existence of an anomaly due to the quake itself. Variations in sea level due to local registered earthquakes $\mathrm{Mw}$ 6.0 to 7.4 range was from 0.10 to $0.30 \mathrm{~m}$; for regional earthquakes of $\mathrm{Mw} 7.3$ and 8.2 were 0.12 and $0.22 \mathrm{~m}$ respectively and to the distant earthquake of Mw 8.0 recorded in Solomon Islands, the change in sea level of the maximum recorded was $0.20 \mathrm{~m}$ in Manzanillo, Colima. It is important to know that earthquakes whether local, regional or distant whose magnitudes are in the range specified here, did not present a risk to the Mexican coast, but do not rely, having to monitor variations in sea level that earthquakes can produce and be aware that you may perhaps occur as a tsunami in Indonesia in 2004 or Japan in 2011.
\end{abstract}

Key words: Sea level, Mexican Pacific, tsunamis, earthquakes.

\section{Introduction}

Tsunamis can be caused by many disturbing agents at sea such as volcanic eruptions, underwater landslides, meteorites and mainly by earthquakes; but not all earthquakes generate tsunamis, they must be caused by the collision of tectonic plates as in the west coast of Mexico, where the Cocos Plate and the subduction Rivera are on the North American plate (Middle America Trench), which comprises between Puerto Vallarta in Jalisco, to Chiapas, in this area the major earthquakes have occurred in the twentieth century along the Middle America Trench [1] and some of them have generated tsunamis.

However the coastal population is becoming aware that in Mexico tsunamis are a real threat, but there is still lack of in Mexico have occurred and may occur,

Corresponding author: Román Rodolfo Vera Mendoza, M. Sc., researcher, research fields: tsunamis, tides, see level variation. perhaps because the biggest casualties have occurred in Mexico City, because the earthquake itself, as the 1985 earthquake that devastated more than 5,000 buildings causing the death of about 6,000 people [2] distracting the attention of the authorities and the general population of the tsunami that occurred with waves of three meters high and causing damage in Lazaro Cardenas, Michoacan [3].

Therefore, it is important to know the history of tsunamis that were generated in Mexico, whose task was performed by Sánchez de Devora [4], published in the Catalogue of Tsunamis on the West Coast of Mexico, whose objective was to ensure that all historical data were available for research purposes, risk assessment and tsunami warning information comprising tsunamis observed and/or recorded on the west coast of Mexico from 1732 to the date of publication of the catalog.

Given this, the present work aims to continue this work of reporting the earthquakes in Mexico and 
elsewhere, and publicize their tsunamigenic potential in Mexican coasts.

\section{Methods}

\subsection{Data Logging}

The sea level data were obtained from automatic tide gauge stations, belonging to the network of tide gauge Navy Mexico. The seismic data were obtained from the Mexican National Seismological Service.

\subsection{Data Processing}

The zero height of the sea level was corrected by subtracting the annual average for each data set, these data were plotted to detect the variation caused by the earthquake by matching the time of occurrence of the earthquake with the tide level.

The series of sea level were filtered to remove the effect of waves, tides and other high-frequency fluctuations may have by applying a Lanczos type low-pass filter with cutoff frequency of 26 hours.

\subsection{Results}

The earthquakes that are listed in Table 1 , were magnitude considered with potential for tsunami generation for Mexico's Pacific coast.
In Fig. 1 the sea level of the tide gauge station of Acapulco, Guerrero represented; the maximum height recorded was around $0.10 \mathrm{~m}$.

The sea level anomalies were analyzed using data from buoys DART (Deep-ocean Assessment and Reporting of Tsunamis). DART buoy in India, located $643 \mathrm{~km}$ northwest of the epicenter, the sea level anomalies did not reach the $0.10 \mathrm{~m}$ high (Fig. 2); in the Mexican Pacific no anomalies in sea level were presented. It is noted that in the first swing mareograms correspond to the pressure changes of water column due to the passage of seismic waves and not oscillation sea level. Buoys DART record changes of pressure of water column, same which result in changes in sea level.

This earthquake was felt in Antiguo Cuscatlan, Nueva San Salvador and San Salvador, also it felt in Honduras and Managua in Nicaragua.

A small tsunami with waves of $0.35 \mathrm{~m}$ was recorded in El Salvador (United States Geological Survey), so the Mexican Tsunami Warning Center through the Tsunami Synthesizer model estimated maximum wave height of $0.12 \mathrm{~m}$ in Puerto Madero, Chis (Fig. 3).

Through the tide gauge installed in Puerto Chiapas,

Table 1 Earthquake occurred during the period of 2012-2015 with tsunamigenic potential for Mexico's Pacific coast.

\begin{tabular}{|c|c|c|c|c|c|c|}
\hline No. & Date & $\begin{array}{c}\text { Time of the } \\
\text { earthquake } \\
\text { (Loca Time } \\
\text { Mexico City) }\end{array}$ & $\begin{array}{c}\text { Near the } \\
\text { earthquake site }\end{array}$ & Magnitud & $\begin{array}{c}\text { Maximum Wave } \\
\text { height (m) in Mexico }\end{array}$ & Figure \\
\hline 1 & 20 -Mar-2012 & $12: 02$ & Guerrero, Mexico & 7.4 & 0.10 Acapulco & 1 \\
\hline 2 & $11-$ Apr-2012 & $03: 38$ & Sumatra & 8.7 & 0 & 2 \\
\hline 3 & 26 -Aug-2012 & $22: 37$ & El Salvador & 7.3 & 0.12 Puerto Chiapas & 3 \\
\hline 4 & $7-$ Nov-2012 & $10: 35$ & Guatemala & 7.3 & 0.30 Puerto Chiapas & 4 \\
\hline 5 & $5-$-Feb-2013 & $19: 12$ & Salomon Islands & 8.0 & 0.17 Manzanillo & 5 \\
\hline 6 & $21-$ Apr-2013 & $20: 16$ & Michoacan, Mexico & 5.8 & 0.15 Lazaro & 6 \\
\hline 7 & $01-$ Capr-2014 & $17: 47$ & Chile & 8.2 & See Table 2 & 7 \\
\hline 8 & $18-A p r-2014$ & $09: 27$ & Guerrero, Mexico & 7.2 & 0.30 Zihuatanejo & 8 \\
\hline 9 & $07-J u l-2014$ & $06: 23$ & Chiapas, Mexico & 6.9 & 0.15 Salina Cruz & 9 \\
\hline 10 & $16-S e p t-2015$ & $17: 54$ & Chile & 8.3 & 0.30 Salina Cruz & 10 \\
\hline
\end{tabular}



Tsunamigenic Earthquakes (2012-2015)

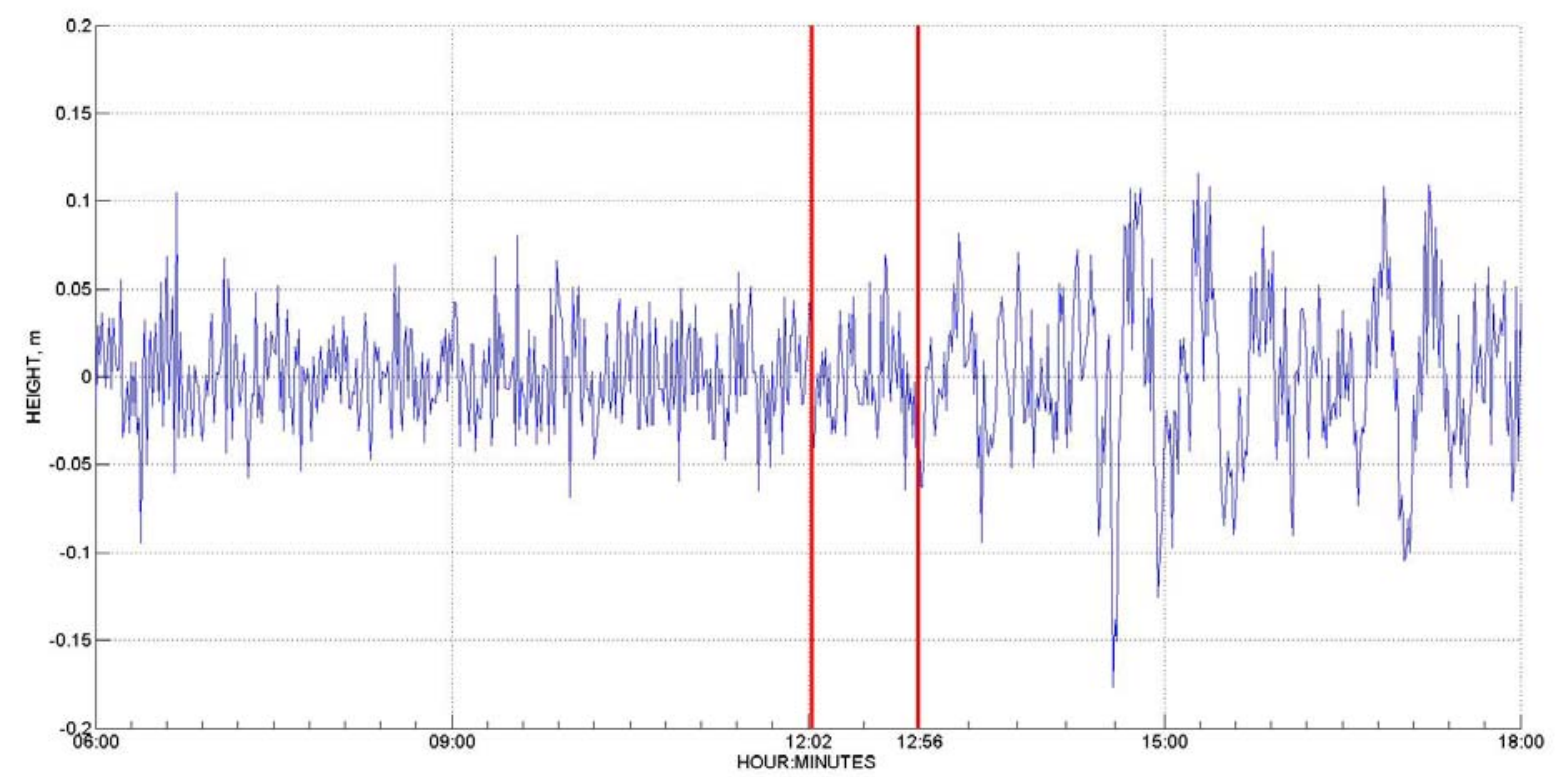

Fig. 1 Change in sea level without effect of the tide, recorded by the tide gauge of Acapulco, Gro., which shows in the first red line from left to right, the time of the earthquake and the second line comes in red that the tsunami arrived (12:56 GMT-6).

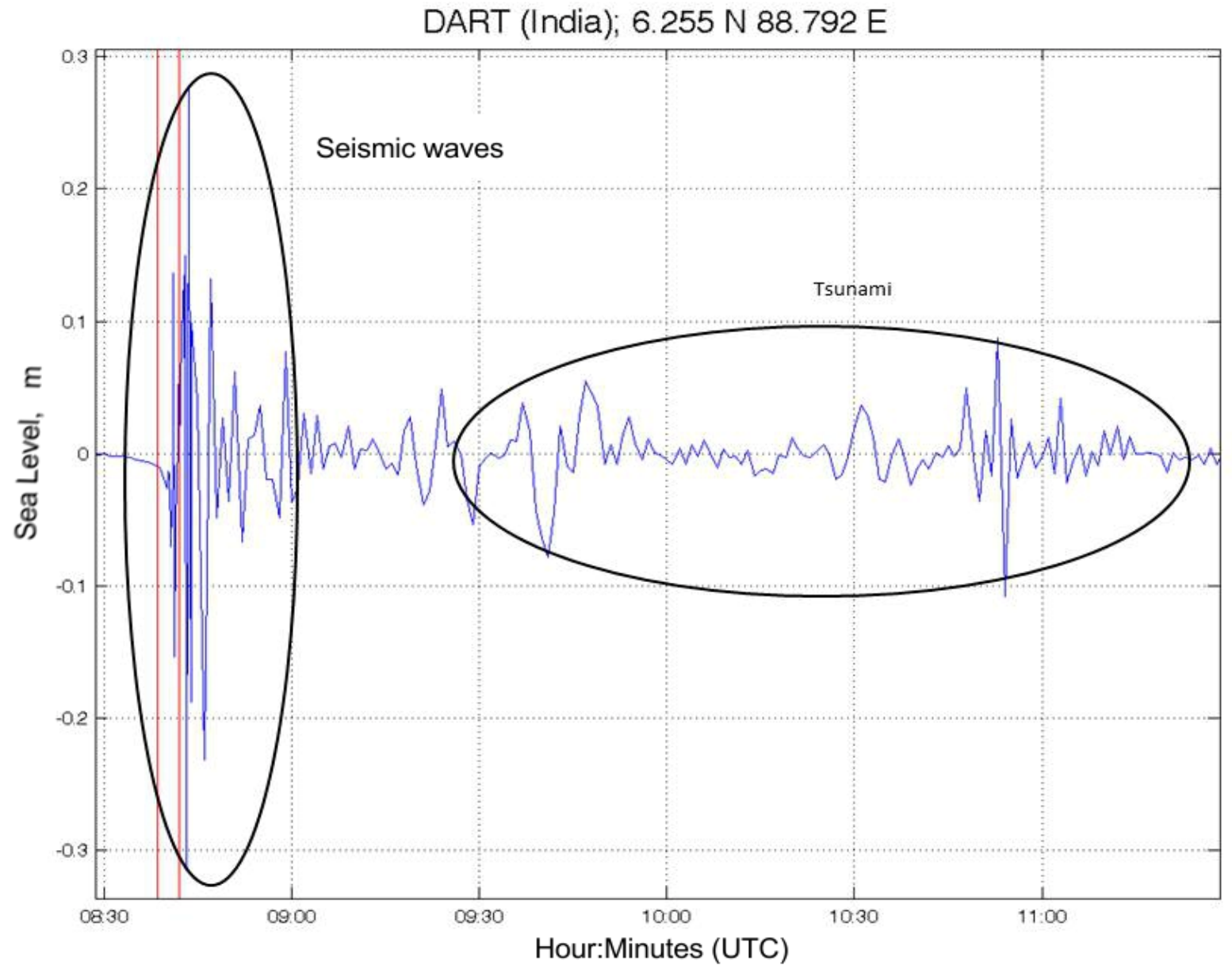

Fig. 2 Anomalies in sea level and tsunami recorded in DART buoy (India). The red lines indicate respectively the origin time of the earthquake and the estimated time of surface seismic waves propagating average speed of $3 \mathbf{~ k m} / \mathrm{s}$. 


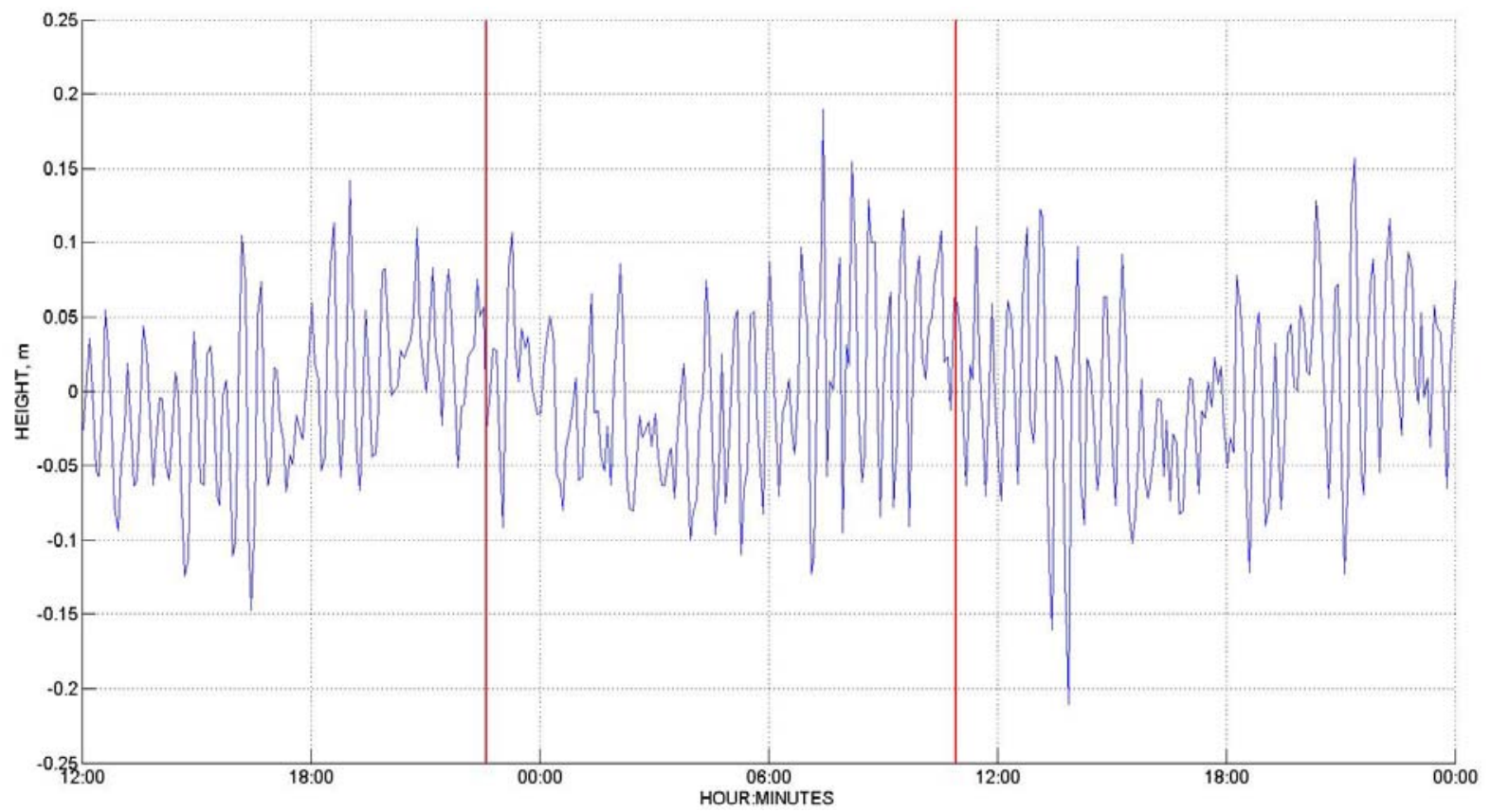

Fig. 3 Sea level anomalies recorded in the Puerto Chiapas tide gauge. The red lines indicate respectively the origin time of the earthquake (22:37 GMT-5) and the estimated tsunami waves reaching the tide gauge time.

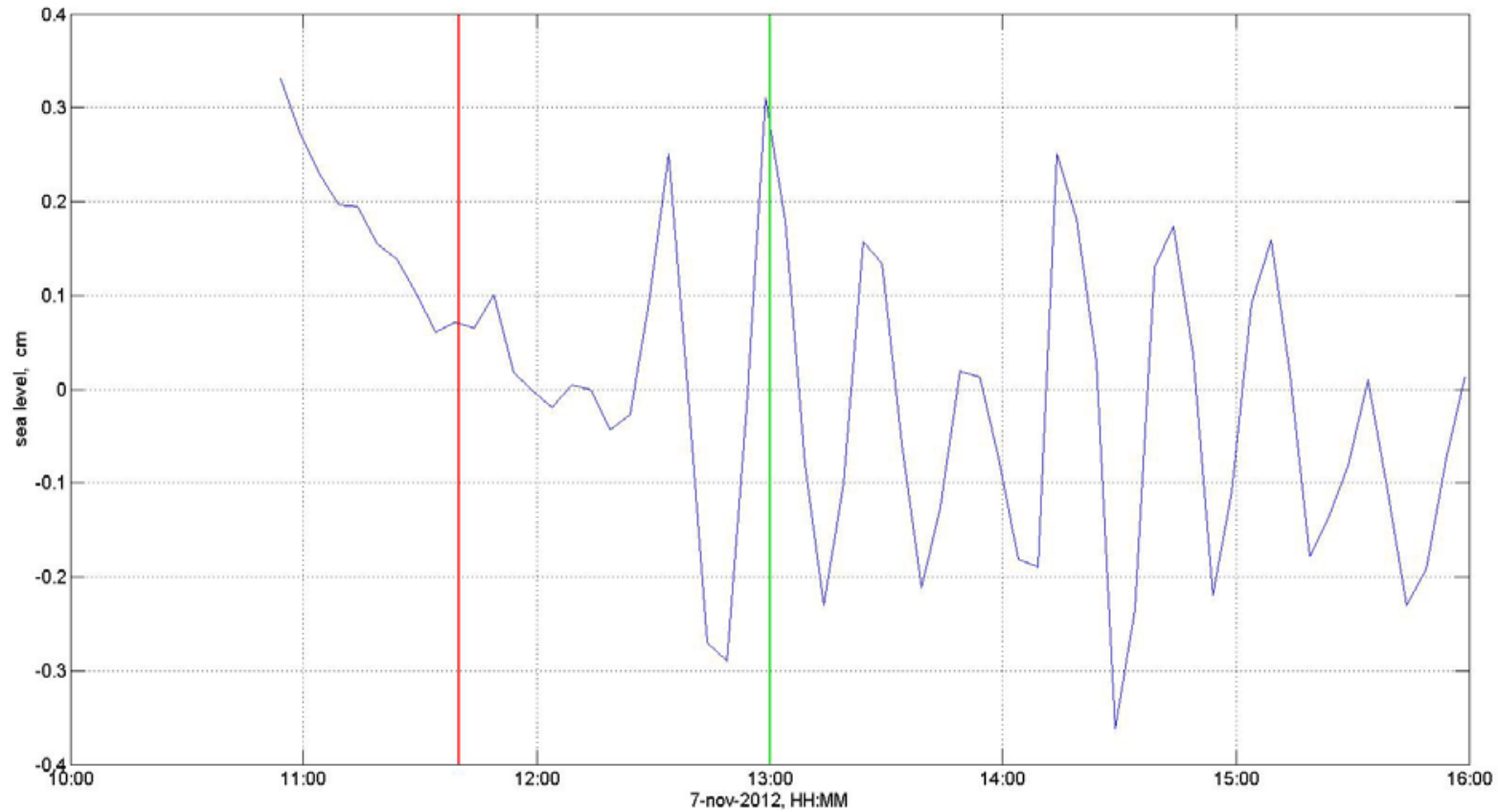

Fig. 4 The red line indicates the arrival time of the wave of Tsunami in the tide gauge Puerto Chiapas, Chiapas, product 7.3 magnitude earthquake November 7, 2012 off the coast of Guatemala. The green line indicates the time and the maximum wave height (GMT-6).

Chis., Mexican Navy Tide Gauge Network, the arrival of the first wave at 11:40 Hrs observed. (1 hour 5 minutes after start of the earthquake) with a height of $0.1 \mathrm{~m}$, and the highest wave was recorded at 13:00 hrs, with a height of $0.3 \mathrm{~m}$ (Fig. 4).
The PTWC (Pacific Tsunami Warning Center) located in Hawaii, it reported involvement in the areas near the epicenter for waves of up to $0.91 \mathrm{~m}$.

At the port of Manzanillo, Colima, the arrival of the first wave occurred at 09:15 (14 hours with 03 
minutes after the earthquake) and the maximum wave height of $0.17 \mathrm{~m}$ was recorded (Fig. 5).

The sea level observations in real time from the Tide Gauge Network Mexican Navy confirmed the absence of significant anomalies in sea level, only indicating the presence of anomalies few tall $0.15 \mathrm{~m}$ in sea level in Lazaro Cardenas (Fig. 6), virtually imperceptible to the population and no risk to port facilities.

In the case of tsunamis from Chile magnitude 8.8 on February 27, 2010 and the magnitude 9.5 on May 23, 1960, both highly destructive earthquakes generated tsunamis, however, they did not cause damage to the Mexican coast.

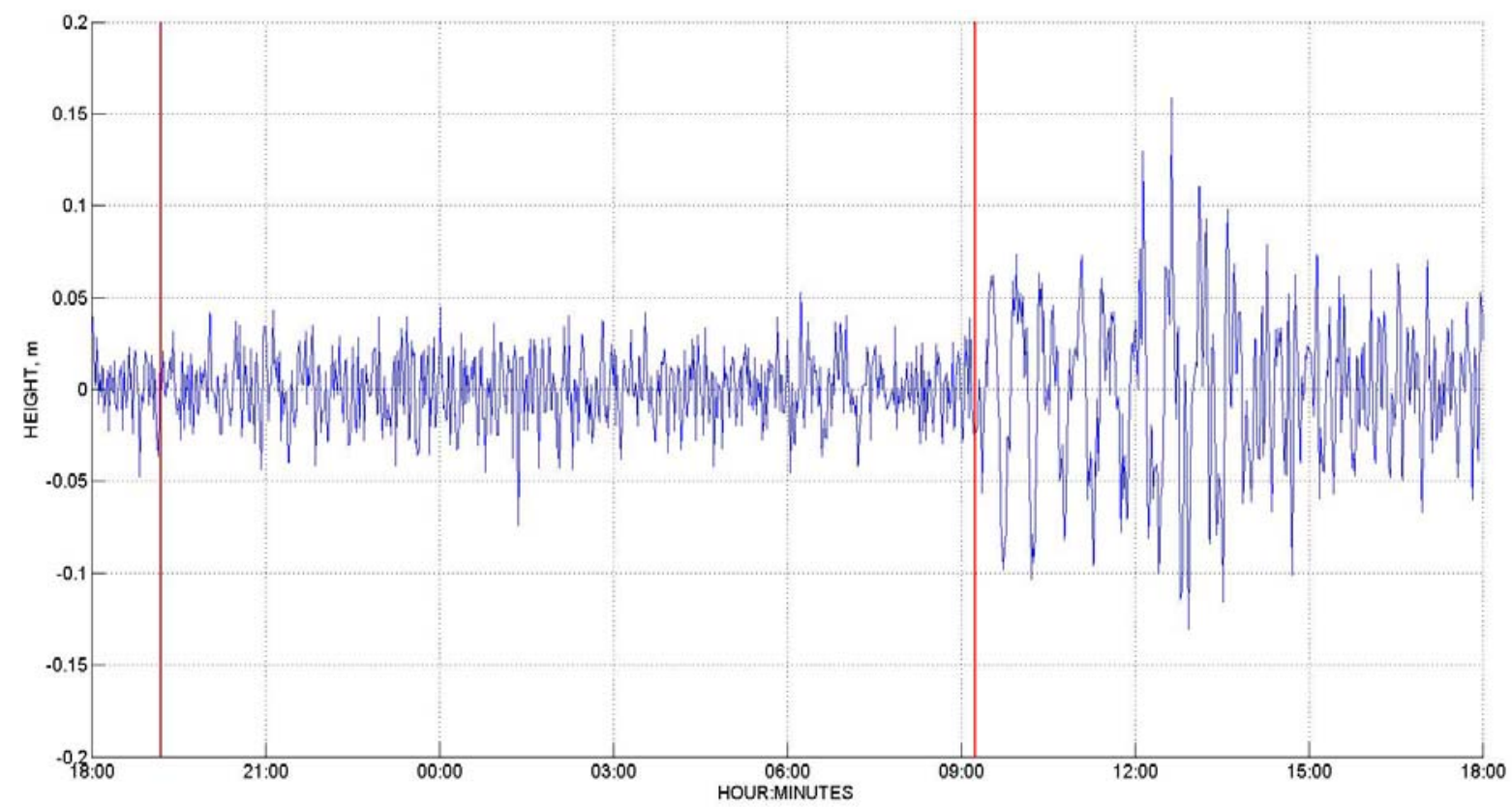

Fig. 5 Sea level registered in Manzanillo, Colima, during the earthquake of magnitude 8.0 at 19:12 hrs (GMT-6) on 5 February 2013. The second red line from left to right represents the arrival time of the tsunami (09:15 hrs. GMT-6).

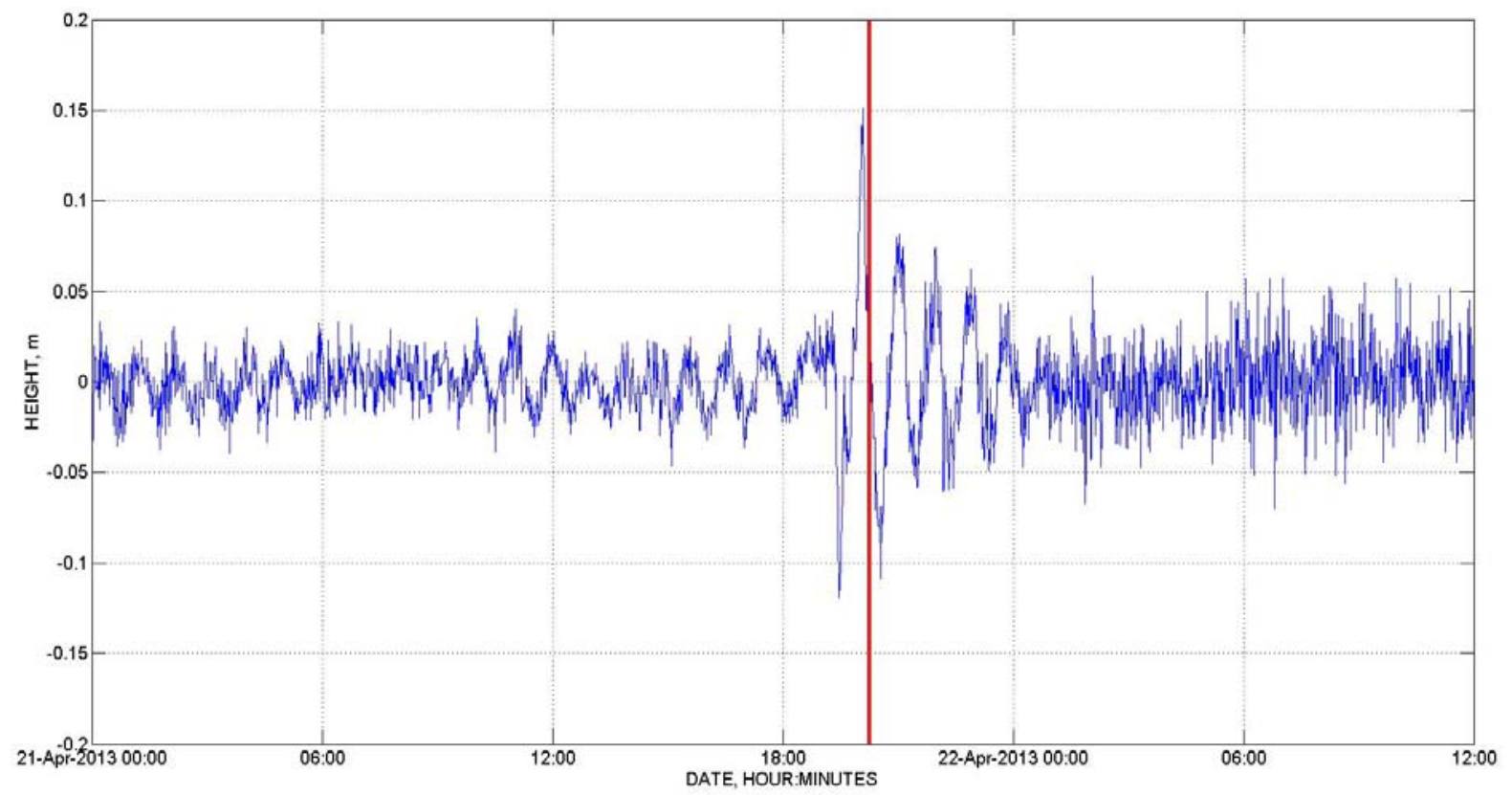

Fig. 6 Sea level recorded in real time at the harbor of Lazaro Cardenas, Michoacan. The red line indicates the start time of the earthquake (20:16 hrs GMT-6). 
This background allowed promptly rule also no danger was expected by the tsunami generated by the magnitude 8.2 earthquake in northern Chile on April 1, 2014.

By using models of tsunami propagation, such as that shown in Fig. 7, as well as the real-time monitoring of changes in the level, it was found that there was no danger to Mexico to register the arrival of the tsunami Puerto Chiapas, the southernmost port of Mexico.

Derived from the monitoring of sea level stations in the Mexican Pacific Coast, changes in sea level heights were recorded that did not represent any risk for the population or for port operations, as shown in Table 2.

The sea level observations in real time from the tide gauge network Mexican Navy confirmed the absence of significant anomalies in sea level, only anomalies indicated the presence of low amplitude 30 centimeters sea level in Zihuatanejo, virtually imperceptible to the population (Fig. 8).

Derived from the tide gauge monitoring station Salina Cruz, Oaxaca, variations in sea level of up to $0.15 \mathrm{~m}$ were recorded forty-five minutes after the quake as shown in Fig. 9.

For the Pacific Coast of Mexico, variations of a few centimeters expected happened after the 8.3 magnitude earthquake in Chile on September 16, 2015, due to reference occurred on April 2014 cited in this article, confirmed tide gauge station in Salina Cruz, Oaxaca, where maximum heights of sea level are observed was $0.30 \mathrm{~m}$ (Fig. 10).

\section{Discussion}

History and instrument data show that the Pacific

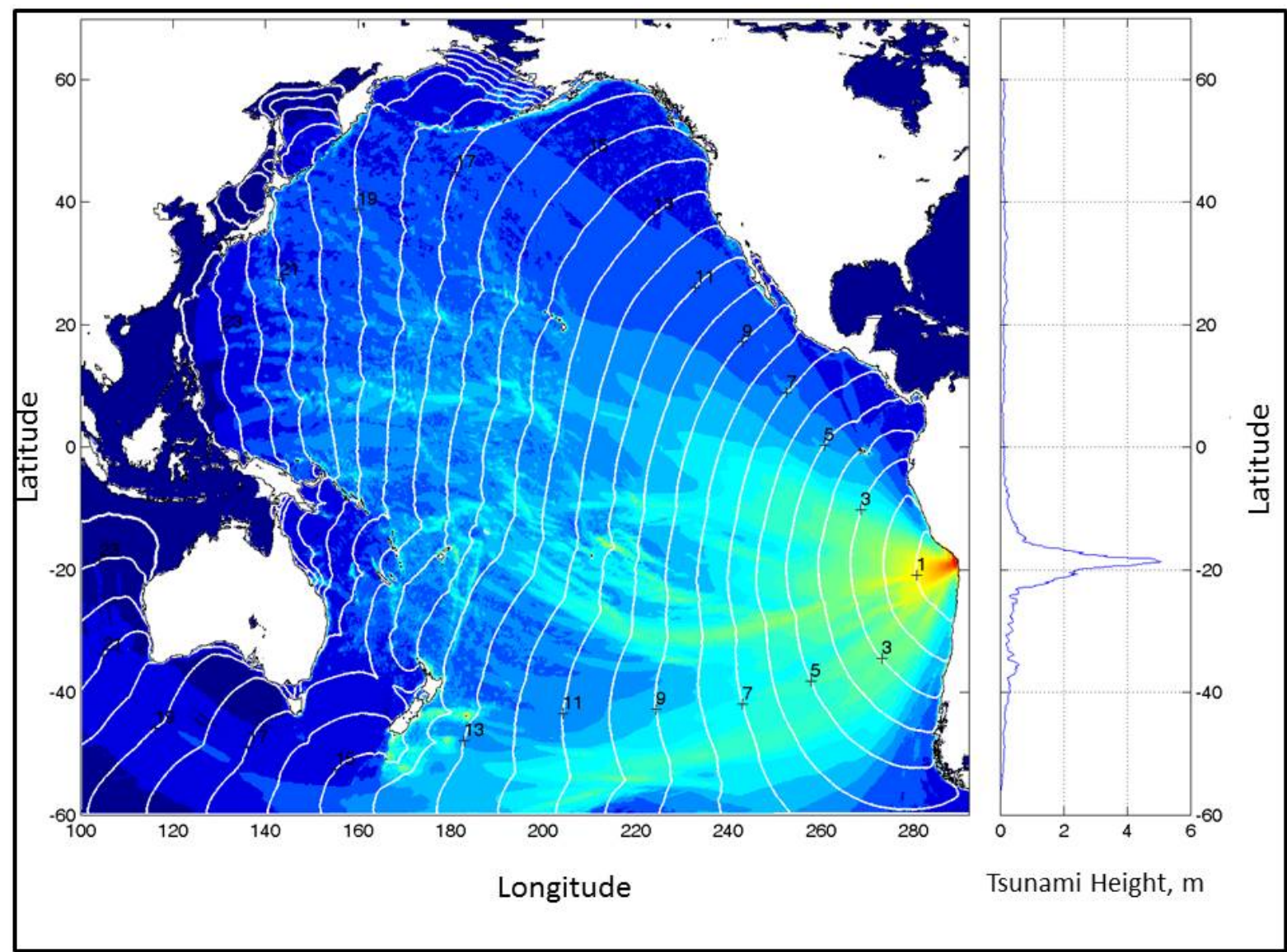

Fig. 7 Letter propagation delay time and tsunami wave height of Chile April 1, 2014. In the right panel of the tsunami height along the coast of the Americas it indicated. The epicenter is located at 20 degrees south on the coast of Chile. 
Table 2 Mexican ports in which variations were recorded sea level.

\begin{tabular}{|c|c|c|}
\hline Mexico Ports & $\begin{array}{c}\text { Arrival time of the Tsunami } \\
\text { (Local Time Mexico City) } \\
\text { 2-Apr - 2014 }\end{array}$ & $\begin{array}{c}\text { Maximum Height (m) / Time } \\
\text { (Local Time Mexico City) }\end{array}$ \\
\hline Puerto Chiapas, Chis. & $01: 57$ & $0.22 / 12: 00$ \\
\hline Salina Cruz, Oax. & $02: 10$ & $0.20 / 02: 44$ \\
\hline Huatulco, Oax. & $02: 33$ & $0.15 / 04: 05$ \\
\hline Acapulco, Gro. & $01: 13$ & $0.14 / 02.40$ \\
\hline Lazaro Cardenas, Mich. & $02: 00$ & $0.5 / 04.02$ \\
\hline Manzanillo, Col. & $01: 57$ & $0.14 / 03: 26$ \\
\hline Isla Socorro, Col. & $02: 55$ & $0.12 / 04: 18$ \\
\hline Ensenada, B.C. & $05: 59$ & $0.10 / 08: 22$ \\
\hline
\end{tabular}

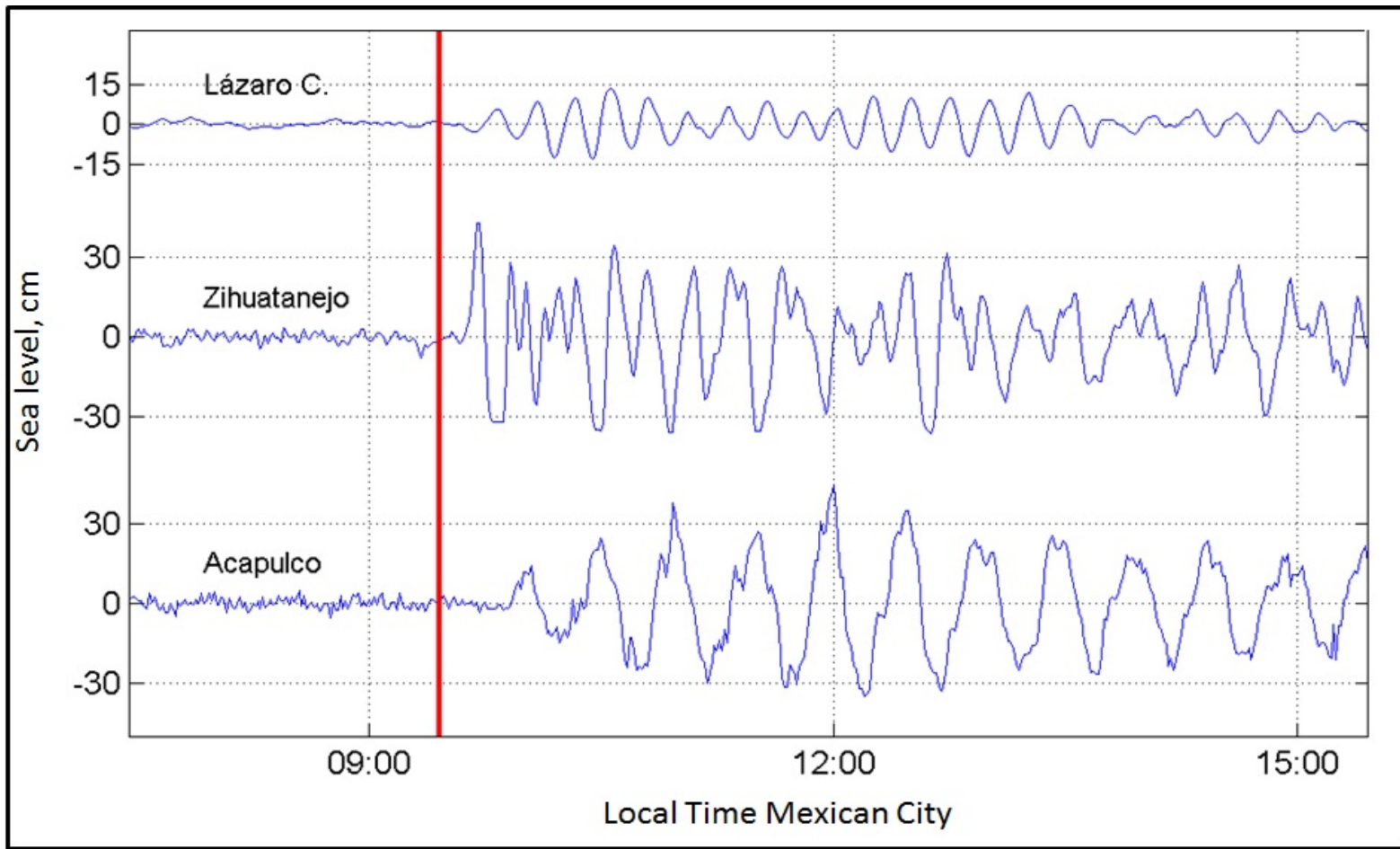

Fig. 8 Observations of sea level recorded in real time on the tide gauge stations of the Mexican Navy, after the earthquake, Guerrero, Mexico, April 18, 2014 of magnitude 7.2.

Coast of Mexico has been exposed to tsunami events; in the last 253 years (1732-1985) 50 tsunamis have occurred, of which 16 were 34 local and distant tsunamis, 14 events that generated local tsunamis with wave heights were 2 to 11 meters. In the period for this study five earthquakes caused local variations in sea level of up to $0.15 \mathrm{~m}$ considering that the maximum magnitude recorded was 7.4 in Ometepec, Guerrero, so it is still waiting for a big earthquake that could generate a tsunami local generating damages to coastal populations.

Can see that the regional earthquakes reported in this paper generated heights of $0.22 \mathrm{~m}$ (8.2 Mw earthquake in Chile, from April 1, 2014), and distant earthquakes caused the increase in sea level of $0.20 \mathrm{~m}$ (earthquake Islands Salomon Mw 8.0 of 5 February 2013) following the pattern of distant earthquakes before, where the waves reached heights less than $2 \mathrm{~m}$ 


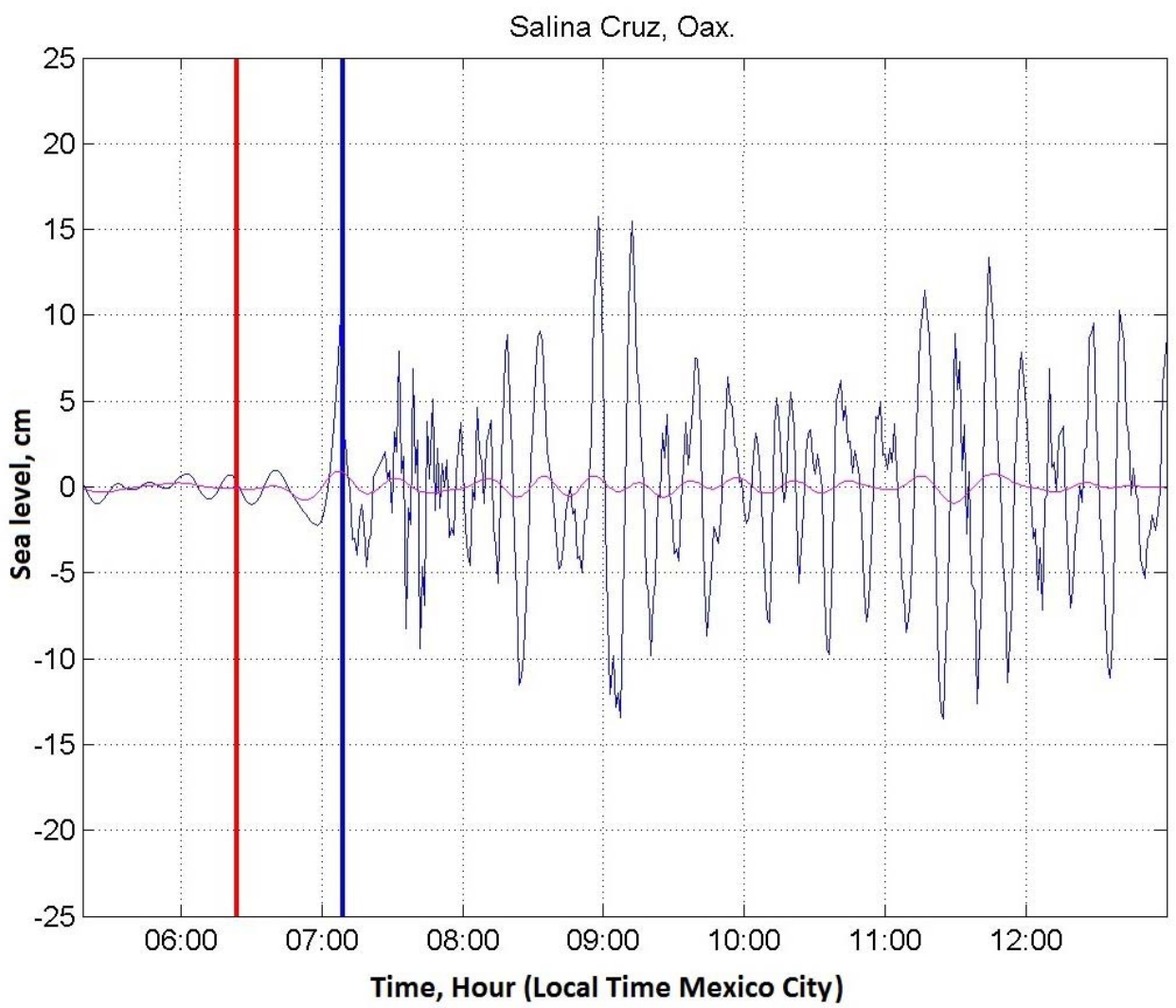

Fig. 9 Variations in sea level recorded by the tide gauge of Salina Cruz, after the 6.9 magnitude earthquake off the coast of Chiapas, on July 7, 2014, where a rising sea of $15 \mathrm{~cm}$ is observed. The vertical red line represents the start time of the earthquake (06:23 hrs GMT-5).

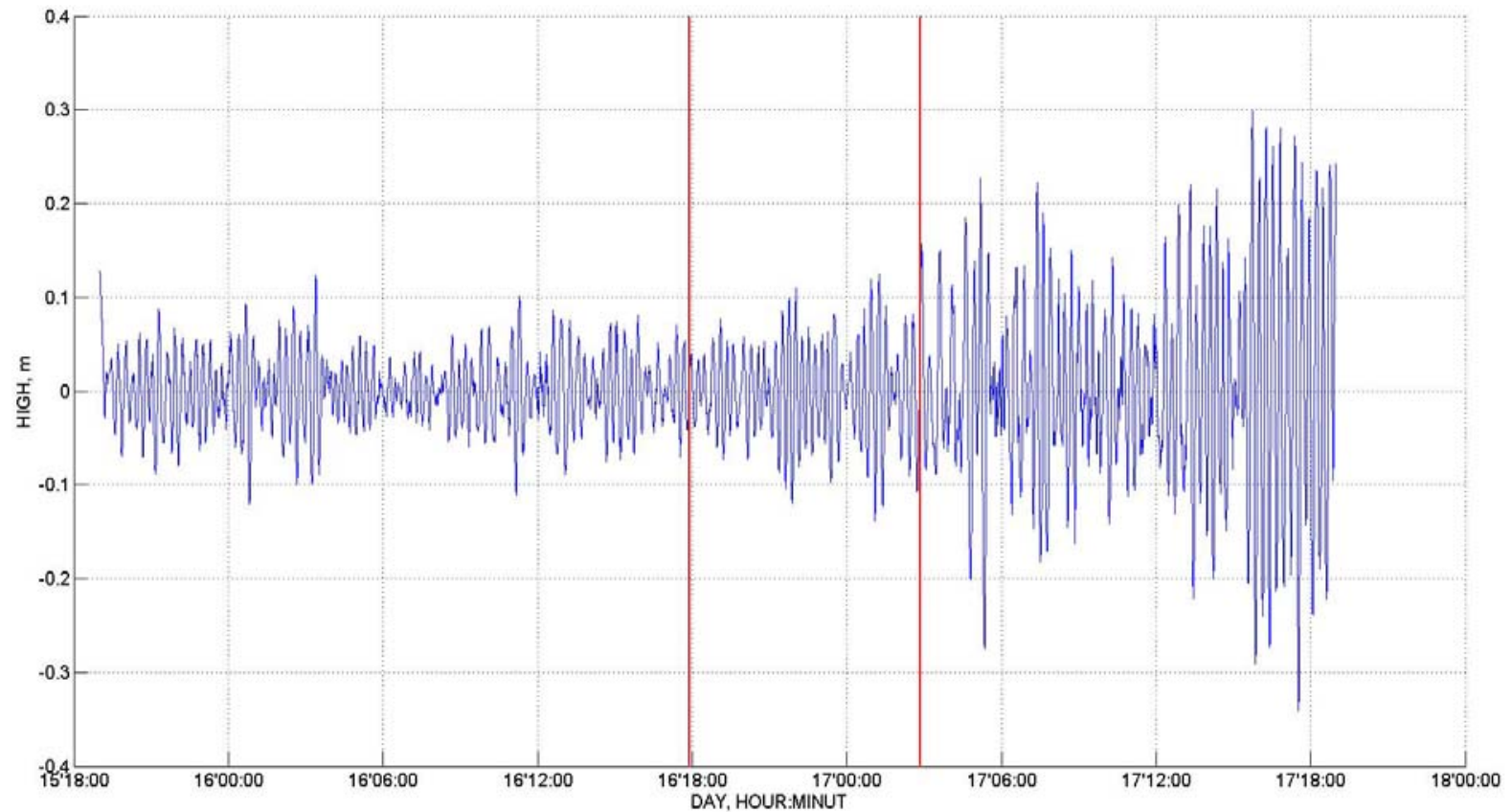

Fig. 10 Variations in sea level recorded by the tide gauge of Salina Cruz, Oaxaca after the 8.3 magnitude earthquake off the coast of Chile on September 16, 2015, where a rising sea of $0.3 \mathrm{~m}$ is observed. The first red line from left to right represents the start time of the earthquake and the second arrival time of the tsunami (GMT-5). 
to the Pacific Coast of Mexico [4].

There is no knowledge that in Mexico has generated similar to Sumatra December 26, 2004, Chile's February 27, 2010 or Japan March 11, 2011 tsunami; however, we cannot rule out the possibility that they occur mainly in the gaps of Guerrero and Tehuantepec, where a long period of time, a major earthquake has occurred [1].

Although major earthquakes are expected in the gap of Guerrero and Tehuantepec, Cotte et al. [5], mentioned that in the gap Guerrero "Slow Earthquake” originate with an approximate recurrence of 4-4.5 years, so it could not be expected that great earthquake as it is releasing energy, however depending on the proximity of the fault they could lengthen or shorten the time of the great earthquake that is expected.

\section{Conclusions}

Variations in sea level in the different ports of the Mexican Pacific, caused by earthquakes described here, did not vary in danger and no wave that could cause harm to people or the naval and port operations.

It is important to note that such changes were only observed through measuring instruments, without being detectable by surface units and coastal population.

The historical records of sea level anomalies caused by earthquakes, are a fundamental basis for the forecast of wave heights in the coming earthquakes allowing give certainty and confidence to the population and the authorities to prevent the cessation of activities in the ports of the country, which would result in strong and unnecessary economic losses that manage to avoid thanks to the actions of alert and prevention.

\section{References}

[1] Kostoglodov, V., and Pacheco, J. 1999. Cien años de Sismicidad en México. Instituto de Geofísica.

[2] Secretaría de salud, 2012. Los Terremotos de 1985. Retrieved August 15, 2015, of http://www.spps.salud.gob.mx/avisos/1120-los-terremo tos-de-1985.html

[3] Abe, K., Hakuno, M., Takeuchi, M., and Katada, T. 1986. "Survey Report on the Tsunami of the Michoacan.” México earthquake of September, 19(1985): 475-81.

[4] Sánchez de Devora, Antonio, J., and Sanz, S. F. F. 1993. Catalog of Tsunamis on the Western Coast of Mexico. World Data Center A for Solid Earth Geophysics, Report SE-50, Boulder, CO.

[5] Cotte, N., A. Walpersdorf, V. Kostoglodov, M. Vergnolle, I. Manighetti. and M. Campillo 2009. "Anticipating the Next Large Silent Earthquake in Mexico.” Eos, 90(21). 